\title{
Chef's Perception on Nutrition and Health
}

\author{
'D. Vandana ${ }^{1}$, D.L.Kusuma ${ }^{2}$ \\ ${ }^{I}$ Research Scholar Department Of Home Science Sri Venkateswara University Tirupati \\ ${ }^{2}$ Professor (Retd) Department Of Home Science Sri Venkateswara University Tirupati \\ Corresponding Author: D. Vandana
}

\begin{abstract}
Of late there is a tremendous increase in the eating out episodes of our population. In order to meet the demand there is an increase in the establishment of Food service units the throughout the country. In the western world the consumers are habituated to eating out. In view of the increase in the incidence of obesity and associated chronic health problem such as CVD, CHD, diabetes mellitus etc. a focus is being given to healthy eating out practices. The study surveyed chef's working in select hotels and restaurants at Tirupati and Tirumala, which is a world renowned Pilgrim centre located in ChittoorDistrict in the state of Andhra Pradesh. The chef's perception on the four aspects vizhealth, nutrition, practices and consumer concerns were assessed in the context of menu planning and food service. The results revealed that in both locations the chef's of hotels showed a better Perception in all four areas when compared to the Chef's of restaurants. The differences were significant out 0.01 percent. The findings also revealed that chefs of restaurants at Tirumala showed good perceptions in the areas of nutrition and health. A low level of perceptions was evident in practicing nutrition and consumer concern. Chef's in general believed that nutrition is important in menu planning. Effortshowever, need to be to facilitate nutrition related practices in the Food cateringunits and increase consumer awareness and healthy eating out habits of consumers. Chefs thus, in strongly believed that nutrition is important in menu planning in food catering institutions, there is a great need to create facilitating environments to convert perceptions into sustaining practices.
\end{abstract}

Keywords: Nutrition, consumers, Chef's perception and menu planning

Date of Submission: 03-07-2017

Date of acceptance: 17-07-2017

\section{Introduction}

In any food service unitthe role of chef is the most crucial factor influencing the variety of food stuffs, culinary effects and flavoring of products. The chef's knowledge, attitude and practices pertaining to nutrition and health are imperative to satisfy the expectations of consumers who are increasingly becoming conscious of nutrition and health. Report on the diets oftenfocus on nutrient intake because histroricallynutrients have been considered the dietary components of interest and because food - consumption surveys were originallydesigned to track them (Kerbetal, 1997). The demand for healthful foods raises the level of expectation and dissatisfaction among consumers when eating away from home (Reicheret al, 1998). A 1995 American Institute of wine and foods,restaurants and institution survey reported that fewer than $10 \%$ of respondants said restaurant foods was nutritionallysatisfactory. The goal of promoting the availability of health ful foods in restaurants and institutions is highlighted in several government and professional initiatives. The institute of Medicine (Reicheretal, 1998) named in sufficient background and training in nutrition and receipe modification among chefs as major barries tooffering healthfull foods in food service establishments. Agoal of Healthy people 2020 is to increase the proportion of restaurants that offer identitiable low fat, low energy food choices that are consistent with the dietary guidelines for Amerieans (DGA)(WWW. Health.gov) In the current scenario with the increasing population growth,urbanization, women employment, the trend has gradually shifted from traditional home food to utilizing the outside sources of food catering centers. On par with the increasing demand of home away foods the incidence of metabolic disorders such as obesity, diabetes, heart diseases etc., also, is on the increase. This situation creates a challenging task to the chef of the food service centers in providing nutritious and healthy food preparations with good taste and economic feasibility. With the advent of increase the establishment in food catering units there is a demand created for trained chefs and other food service management personnel.However, the recruitment is not always based on technical skill training but often an experienced person may be performing as a chef in an establishment. In this ground back the present study focused on understanding the levels of chef's perception knowledge \& practices in relation to nutrition, health and consumer concern. 


\section{Review Of Literature}

Consumes and food service operations view eating out as a necessity with today's fast paced lifestyle (Spence, 1995, Stratus, 1994). The frequency of eating away from home has risen by more than two thirds over the past two decades and commercially prepared food accounts for $34 \%$ of the typical persons, total calorie intake (Hunter, 2000). According to a report issued by the United States Department of Agriculture (USDA 1998) more than two out of three adults say that going out to restaurant with family and friends not only offers an opportunity to socialize but optimize their time by dispensing the cooking and cleaning task. USDA also reported that the nutrient content of meals consumed away from home is failing to keep pace with nutritional improvements in home prepared meals. Eating away from home has a tremendous impact on overall health (National Restaurant association, 2000). One goal of the healthy people 2000 National Health Promotion and Diseases prevention program is to increase the proportion of restaurants and other institutional food service operators that offer identifiable low fat low calorie food choices to atleast 90 percent. To accomplishthis, consumers must adapt home eating habits to the commercial environment. Nutrition education for chefs is crucial if restaurants are to stay competitive, as studies has shown that healthful food will be accepted by customer only if the food appeals to the senses, looks exciting and tastes good (Rouslin and vierie,, 1998). Riechier and Dalton (1998), found that although chefs were practicing some health food preparation techniques, the factors such as time, taste and training still posed barriers. In this study the chefs surveyed by the researcher did not think that consumers were concerned about nutrition. Center of Science in the public interest found that 74 percent of adults considered healthy choices is an important factor when selecting a restaurant (Lewis, 1994). The nutrition expertise of chef is a key component in the continuity of effort to convince consumers to change their eating habits and to seek out healthy food items when eating out. Rouslin and Veria (1998), found that chef's are becoming more nutrition aware and responsive to customers demands for healthful menu items. However, some studies concerning the importance of nutrition in the consumer selection of commercially prepared foods show conflicting results. Restaurants and other food service outlets are important venues for nutrition programs promoting recommendations toreduce the fat intake content in menus (FitzPatrick et.al 1997). The escalating of eating out highlights the importance of the chef's role in offering and preparing healthful food. TheCurrent study was designed to examine the knowledge and practicesof chefs on health and nutrition and attitudes in menu planning atworkplace.

\section{Methodology}

For the purpose ofassessment of chef's perception on nutrition and health chefs from 20 hotels and 20 restaurants from Tirupati and 10 restaurants from Tirumula were purposively selected from the total number of 150 food cateringcenters. As the first step the food catering centers were approached in view of their leading role within the food catering industry and were explained in detail about the study. Later their acceptance to participate in the study was obtained. The schedule was developed with expert suggestion and were standardized through a pilot study. The schedule contains with a total of 25 questions in which first part of schedule include 5 questions on demographic information, such as position, qualification, gender age and work experience in the respective establishments where the chefs are currently working. The Second part of the schedule contains 20 questions aimed at assessing the chefs perception towards health, nutrition, nutrition practices while preparing the food and their concern towards customers. Respondents were asked to use 5 point linkert scale where 1 stands for strongly disgree, '2'disagree,'3' neutral, '4' agree, '5' stronglyagree. The food trade centers were categorized based on the years of establishment. The data was collected through personal enquiry from the official records available at Tirupati municipality and Revenue department of Tirumala. As a first step the food catering centers were approached in view of their leading role within the food catering industry and their acceptance to participate and were explained in detail about the study. The schedule was distributed to 50 selected chefs, who were willing to participate. 20 chef's from hotels and 20 chef's fromrestaurants of Tirupati and 10 chef's from restaurants of Tirumula. The opinion regarding nutrition and health information, their knowledge and practices, consumer concern was taken and analyzed statistically by SPSS - Statistical package for the social sciences and the mean of the responses (scores) were calculated through ANOVA to know the significant difference t-test or f-test in the attitudes and practices of chef's working in different food catering centers.

\section{Results And Discussion:}

Table No.1 Demographic profile of the Respondents (Chef's)

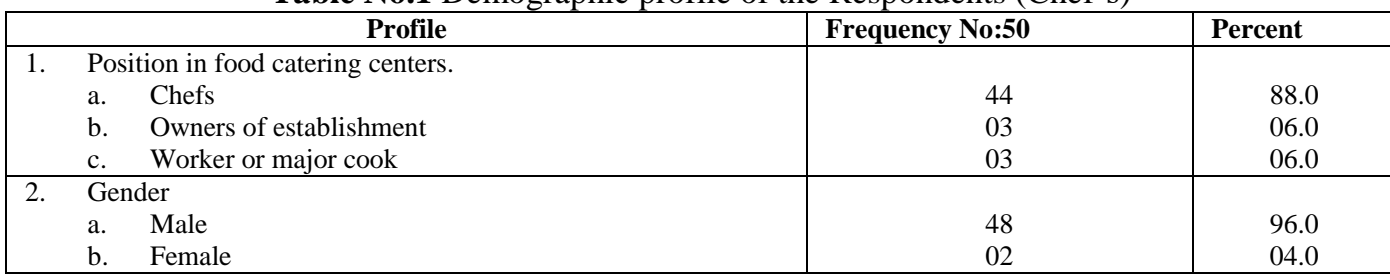




\begin{tabular}{|l|r|r|}
\hline 3. & Age of Respondents & \\
a. 21-30 yrs & 18 & 36.0 \\
b. 31-40 yrs & 28 & 56.0 \\
c. 41-50 yrs & 04 & 08.0 \\
\hline $4 . \quad$ Education qualification & 19 & 38.0 \\
a. HMCT Degree & 20 & 40.0 \\
b. HMCT Diploma & 06 & 12.0 \\
c. GRADUATE (General) & 05 & 10.0 \\
d. Inter/SSC & & \\
\hline Work Experience & 14 & 28.0 \\
a. > 5 years & 33 & 66.0 \\
b. 5-10 years & 03 & 06.0 \\
c. 10-15 years & & \\
Type of the Establishment & 20 & \\
a. Hotels & 30 & 60.0 \\
b. Restaurants & & \\
\hline
\end{tabular}

Table No.1 shows the profile of the sample respondents in which 88 percent were designated as chefs and six percent were owners of the establishment and remaining 6 percent were designated as major cooks Ninety six percent (48.No) were male respondents and four percent were females. The majority of chefs were aged between 31-40 yrs (56 percent) and 36 percent were between 21-30 yrs and 8 percent were above $40 \mathrm{yrs}$. Regarding education majority of chefs 40 percent were diploma holders, 38 percent graduates and 10 percent were SSLC holders, 6 percent were having 10-15 yrs of experience, majority 66 percent of chefs have 5-10 yrs experience and 28 percent have below5 yrs experience.

Table No.2 Shows the descriptive analysis regarding chefs perceptions on four attributes.

\begin{tabular}{|c|c|c|c|}
\hline Sl.No & Perception Attributes & Weighted Scores & Weighted Mean \\
\hline \multicolumn{4}{|c|}{ Perception on Health } \\
\hline 1. & Low fat recipes are good for health and to maintain body weight & 184 & 3.68 \\
\hline 2. & $\begin{array}{l}\text { High fat recipes increase bad cholesterol and increase risk of heart } \\
\text { diseases }\end{array}$ & 199 & 3.98 \\
\hline 3. & $\begin{array}{l}\text { Diabetic clients (or) Consumers require more of vegetables, fiber and } \\
\text { low fat and low energy foods. }\end{array}$ & 186 & 3.72 \\
\hline 4. & $\begin{array}{l}\text { Milk and milk products are always good for health; helps growth and } \\
\text { gives good quality proteins and calcium }\end{array}$ & 178 & 3.56 \\
\hline 5. & Fish, Prawns and Seafood are good for health than meat products & 166 & 3.32 \\
\hline \multicolumn{4}{|c|}{ Perception on Nutrition } \\
\hline 6. & $\begin{array}{l}\text { Eggs, chicken and meat provide good amount of quality protein and } \\
\text { iron. }\end{array}$ & 166 & 3.32 \\
\hline 7. & Vegetable and fruit salads provide essential vitamins and more fiber & 149 & 2.29 \\
\hline 8. & $\begin{array}{l}\text { Always a combination of cereal and pulses enhances the nutritive } \\
\text { value. }\end{array}$ & 136 & 2.27 \\
\hline 9. & $\begin{array}{l}\text { Germination and fermentation of foods increases the nutritive value } \\
\text { in terms of protein and vitamin ' } \mathrm{C} \text { ' }\end{array}$ & 181 & 3.62 \\
\hline 10. & Recipes like Pongal, idli, vadaetc are nutritious and goo for health & 211 & 4.22 \\
\hline \multicolumn{4}{|c|}{ Perception on Nutrition practices } \\
\hline 11. & $\begin{array}{l}\text { Nutrition principles are followed in every day in food selection and } \\
\text { menu planning }\end{array}$ & 108 & 2.26 \\
\hline 12. & $\begin{array}{l}\text { Nutritious selections of foods plays an important role in Planning of } \\
\text { Menus and catering services. }\end{array}$ & 117 & 2.34 \\
\hline 13. & Preparing low fat recipes in hotels is a challenging task. & 176 & 3.52 \\
\hline 14. & $\begin{array}{l}\text { Suitable cooking methods, color combinations, nutritive values are } \\
\text { considered in selection of recipes and menus. }\end{array}$ & 140 & 2.8 \\
\hline 15. & $\begin{array}{l}\text { Quality standards are followed in the preparation and service of } \\
\text { finished products }\end{array}$ & 191 & 3.82 \\
\hline \multicolumn{4}{|c|}{$\begin{array}{ll}\text { Perception on Consumer Concern } \\
\end{array}$} \\
\hline 16. & $\begin{array}{l}\text { Consumers do take nutrition into consideration while selecting and } \\
\text { ordering menu }\end{array}$ & 165 & 3.30 \\
\hline 17. & Consumers are concerned about fat in their diet. & 107 & 2.14 \\
\hline 18. & $\begin{array}{l}\text { The frequency of restaurant eating will have impact on individual } \\
\text { Nutritional health status. }\end{array}$ & 161 & 3.22 \\
\hline 19. & $\begin{array}{l}\text { All the recipes are prepared considering different types of clientele } \\
\text { and their halth conditions }\end{array}$ & 146 & 2.92 \\
\hline \multirow[t]{2}{*}{20.} & $\begin{array}{l}\text { Quality holds more importance than quantity in the maintenance of } \\
\text { one's health. }\end{array}$ & 93 & 1.86 \\
\hline & Total & 3180 & 63.6 \\
\hline
\end{tabular}


The table no.2 shows that respondents strongly agreed (4.22) with only one statement that "the south Indian recipes are good for health and nutritious" The statement "Quality holds more importance than quantity and maintains ones health" received lower mean scores (1.86) and falls in the disagree statement category. All other statement were ranked between disagree, neutral and agreed scale.

Perception on health was ranked betweenneutral to agree scale, all statements got above neutral scores ranging from 3.32 to 3.98 indicating that chefs have good perception on fat and cholesterol intakes through diets and their consequences on health. The statements were mainly focus on understanding levels, on the "role of low fat and high fat recipes in health maintenance" (3.68), "Importance of milk and milk products" (3.56) "Requirement of vegetables, fiber for diabetic clients" (3.72) and "Preference of sea foods over the meat products" (3.32). The respondents were in agreement with all the above statements.Of the five statements on perception on nutrition knowledge and the corresponding health significance viz., "Vegetables and fruit salads providing fiber and essential vitamins" (2.29), "enhancement of nutritive value with cereal and pulse combination" (2.27), "nutrient enrichment with the food processing techniques of germination and fermentation" (3.62), the statement on and "healthyness of south Indian recipes" (4.22) ranked high with strongly agree option by the chefs and all other statement ranked between neutral to disagree.

Regarding the statements on nutrition practices, two statements were viz., "follow and attain different quality standards in the preparation and service of recipes" (3.82) "Preparing low fat recipes in hotels is a challenging task" (3.52) received agreed practices.Other three statements vize "following nutrition principles every day in selection and planning of menus" (2.26)"Nutritious selection and consider suitable cooking methods, color combinations oneconsideredwhile selection of recipes in everyday preparations (2.8) were between disagree to neutral.

Regarding the statement on consumer concern two statements viz., "Quality holds more importance than quality" (1.86) "Consumers are concerned about fat in their diet" (2.14) ranked lower mean scores, indicating disagreement with the statements.Other statements "Consumer does take nutrition into consideration while selecting and ordering a menu" (3.30) "The Frequency of restaurant eating will have impact on individuals nutritional and health status" (3.22) were ranked between neutral and agree. Another statement "all recipes are prepared considering different types of clientele and their health conditions" (2.92) ranked between disagree and neutral.

Table No.3 Mean scores and comparison of perception in selected chefs in hotels and restaurants of Tirupati and Tirumala

\begin{tabular}{|c|c|c|c|c|c|c|}
\hline Sl. No & Chefs Perception & \multicolumn{2}{|c|}{ Tirupati } & \multirow{2}{*}{$\begin{array}{c}\text { Tirumala } \\
\text { Restaurants } n=10 \\
\text { Mean } \pm \text { SD }\end{array}$} & \multirow[b]{2}{*}{$\begin{array}{r}\text { Totaln }=50 \\
\text { Mean } \pm \text { SD }\end{array}$} & \multirow[b]{2}{*}{ 'F'-values } \\
\hline & & $\begin{array}{c}\text { Hotels } \mathbf{n}=20 \\
\text { Mean } \pm \text { SD }\end{array}$ & $\begin{array}{c}\text { Restaurants } n=20 \\
\text { Mean } \pm \text { SD }\end{array}$ & & & \\
\hline 1. & $\begin{array}{ll}\text { Perception } & \text { on } \\
\text { Health } & \end{array}$ & $\begin{array}{c}23.75 \\
( \pm 1.164)\end{array}$ & $\begin{array}{c}17.70 \\
( \pm 1.261)\end{array}$ & $\begin{array}{l}18.30 \\
( \pm 0.95)\end{array}$ & $\begin{array}{c}20.24 \\
( \pm 3.120)\end{array}$ & $151.556 * *$ \\
\hline 2. & $\begin{array}{l}\text { Nutrition } \\
\text { knowledge }\end{array}$ & $\begin{array}{c}22.90 \\
( \pm 1.37)\end{array}$ & $\begin{array}{c}15.80 \\
( \pm 1.79)\end{array}$ & $\begin{array}{l}17.70 \\
( \pm 0.95)\end{array}$ & $\begin{array}{c}19.02 \\
( \pm 3.58)\end{array}$ & $117.585^{* *}$ \\
\hline 3. & Nutrition practices & $\begin{array}{c}20.15 \\
( \pm 2.23)\end{array}$ & $\begin{array}{c}14.35 \\
( \pm 1.08)\end{array}$ & $\begin{array}{c}14.20 \\
( \pm 1.55)\end{array}$ & $\begin{array}{c}16.64 \\
( \pm 3.35)\end{array}$ & $69.605 * *$ \\
\hline 4. & Consumer concern & $\begin{array}{c}20.45 \\
( \pm 2.16) \\
\end{array}$ & $\begin{array}{r}12.95 \\
( \pm 1.43) \\
\end{array}$ & $\begin{array}{c}12.20 \\
( \pm 0.92) \\
\end{array}$ & $\begin{array}{c}15.80 \\
( \pm 4.189) \\
\end{array}$ & $125.65 * *$ \\
\hline & Overall Score & $\begin{array}{r}86.35 \\
( \pm 5.41) \\
\end{array}$ & $\begin{array}{r}60.80 \\
( \pm 2.82) \\
\end{array}$ & $\begin{array}{c}62.40 \\
( \pm 3.98) \\
\end{array}$ & $\begin{array}{c}71.34 \\
( \pm 13.08) \\
\end{array}$ & $208.065 * *$ \\
\hline
\end{tabular}

Note: $(* *$ Significant at $\mathrm{p}<0.01 *$ Significant at $\mathrm{P}<0.05$ NS:Not significant)

( ): Scores in Paranthesis is standard deviation

The results from the table No.3 expressed significant difference on health perceptions of hotel chefs $(23.75 \pm 1.164)$ in relation to restaurants of Tirupati(17.70 \pm 1.26$)$ and Tirumala $(18.30 \pm 0.95)$. The nutrition knowledge of chefs in hotels are far better $(22.90 \pm 1.37)$ and significant at 1 percent level than chefs of

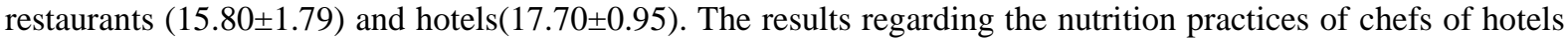
got better mean score $(20.15 \pm 2.23)$ than chefs of restaurants at both locations $(14.35 \pm 1.0814 .20 \pm 1.55)$ which was significant at 0.01 percent level. Even in perception on consumer concern, the hotel chefs were found to be significantly better $(20.45 \pm 2.16)$ than the chefs of restaurants at Tirupati (12.95 \pm 2.16$)$ and Tirumala

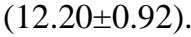

Results indicate that chefs have better perception on health awareness when compared to other perceptions as evidenced from the higher mean score (20.24 \pm 3.12$)$. Chefs have the knowledge about food choices, reduction of fat in diets, requirement of more vegetables and fiber for diabetic clients and for ones own health.Chefs require dietary modifications to improve health and to apply this knowledge while preparing recipes and menus in food catering centers. By practicing appropriate cooking methods and including fiber rich foods, which can prevent diseases and manage lifestyles. 
A majority of the chefs surveyed in this study agreed with the statement that preparation of low fat recipes in hotels is a challenging task. These results match with those observations of Richer and Dalton (1998),Possibly indicating a change in attitude towards low fat recipe development in hotels. Chefs agreed to the fact that low fat recipes were good for health but the levels of practicing of acquired knowledge might be varying. The chefs might be aware of the fact that high fat increases the risk of heart diseases, but the knowledge level towards bad cholesterol was not upto the mark. Chefs either in the hotel or restaurants simply are ready to prepare the recipes as per their task, culinary requirements of food catering centre menus. Chefs usually make little efforts to provide food for customers with different disease conditions.

The second aspect of chefs perceptions on Nutrition knowledge has got mean score of $(19.02 \pm 3.58)$ lower than health awareness statements but ranked second probably due to the reason that, chefs were not strong enough in their perception on nutrition but simply adhered to their culinary skills instead ofemphasingthe practices of preparing better nutritious recipes.No formal food guidelines for reference is available at work place to practice nutrition knowledge in food production. This barrier may be over come with the promotion of nutrition guidelines as stereotype in all the food catering establishments.

The chefs were practicing nutrition principles knowingly such as salad preparations, combinations of recipes using sprouts and fermented foods and using variety of ingredients with maximum food groups as far as possible. These were the few probable factors for scoring good meanscores but showed significant different at 0.01 percent level. Regarding chefs perceptions on consumer concern got mean scores of $(15.80 \pm 4.19)$ ranked low scores than other perception shows that chef'scooks for the sake of customers but not in view of the patients clintleeveryday. The clients need to select the recipes suitable to them according to their taste and rituals. The customer wants healthier menu items but their purchasing behavior doesn't match with their select items. Taste, quality and quantity remains the most important issue while ordering food.Rouslin and Vieria (1998) found that chefs were interested in applying more nutrition principles in commercial food services, and stated thatapplication of nutrition practices is a continuous task.

The overall results on the total scores revealed f-value significant at one percent level in all four areas of perception of chefsamong the three food catering centers. This probably may be due to maximum functioning satisfaction levels and wider range of facilities at hotels than restaurants of Tirupati and Tirumala.

The majority of chefs of hotels for all four perceptions might strongly agree to the fact that they have high perception in health statements awareness of nutrition knowledge but executing the perceptions may be vary. The chefs follow the standards of catering policy and they cook for their customers and having limitations to practice in nutrition principles in a hotel. Hotel chefs got high score which may be attributed due to their better qualifications and experience status. They were having greater experience in cooking, planning and a better exposure to different types of menu preparation, variety of recipes, catering to different types of people and have more exposure to food ingredients and varities in preparations. The importance given to the chefs in the interest of increase customer satisfaction and the development of towards hotel industry. Hence, the hotel management are recruiting better and qualified chefs which goes a long way in creating good will in the community. In restaurants the chef's obtained low scores than those of chefs of hotels may be due to less exposure and experience. The findings obtained revealed that, chefs of the Tirumala restaurants are good and maintain relatively better, than those of Tirupati restaurants.In spite of the continuous rush during the meal times of this highly reputed piligrim center.

However, within the narrow boundariesthe chefs were good at certain nutrition practices such as using several foods and vegetables, in a variety of salad preparations, use of cereal and pulse combination recipes, use of nuts available and oilseeds in different chat masalas etc. These practices might have contributed towards the better scores in nutrition practices. The majority of the restaurants report that although customer wants healthier menu items, their purchasing behavior does not match their stated intension (Tones, 1999). Taste remains the most important issue when ordering food. The results of the study coincide with the earlier observations through the neutral responses to the statements such as "consumers take nutrition into consideration while ordering menus", disagree to neutral scale for the statement "consumers are concerned about fat in their diet".

Commercial food service operators may wish to offer more nutrition conscious items but are unable to do so due to uncertainties in its profitability. In other words, customers who say they want healthy food must request and order healthy food on a regular basis only then will operators find it necessary to modify the menu selections.

\section{Conclusion}

The study projects on the fact that though chefs have moderate to good perception of nutrition health, nutritionenvironmentandattributes Limitations are persisting in the differenttypes food catering centers. This situation needs to altered with offering consumer education and further strengthening the standards of skills of the chefs. The study emphasizes the importance of providing nutrition education to chefs and it is an Opportunity for dietitians to market education that will teach nutritional requirement and empower chefs to accept responsibility for healthful menu planning. 
The public interest in nutrition combined meals eaten away from home and increase the incidence of chronic diseases, represents a challenge and responsibility of today's chefs in different catering institutions. The chefs strongly believe that nutrition is important in menu planning, however there is a great need to create facilitating environments to put perceptions into sustaining practices.

\section{References}

[1] Reicher, G. and S.Dalton (1998), "Chefs attitudes towards healthful food preparation are more positive than their food science knowledge and practices".J.Am.Diet.Assoc.98-165-169

[2] Rouslin. J and S.Vieria (1998) "Recipe for success; culinary and nutrition education". Topics in clin. Nutrition., 13:20-26

[3] Hunter, B.T(2000) “America's eating habits consumers”Res.83, 10-15USDA - U.S Department of agriculture, Economic Research service (USDA/ERS). 1998. Food service sales by industry segment expected july, 1998.

[4] Spence, K. (1995) "The healthy menu"part 3, Restaurant and Institutions, 15 31-48

[5] Lin, B.H.J.Guthrie and E.Frazao (1999) "Away from home foods increasing important to quality of the American", Diet (USDAERS, agriculture information bulletin number 749, Washington, DC,USDA.

[6] National Restaurant Association (2000). "Meal consumption Behavior - 2000".

[7] Lewis, C., (1994). "A case of talking thin and eating food frozen food Age" 43:4.

[8] Jones, W., (1999). "New wealth from health",Restaurants Hospitality 83.98-102

[9] Indian food service story (2011).Maple capital advisors, publication limited maple sector and research team - India.

[10] US Department of Agriculture center for Nutrition policy and promotion. A look at the Diet of Pregnant women. Nutrition Insignts. Insight 17, April 2000.

[11] Rostler.S(2002). "More Americans say diet and exercise important to health". Health headlines Reuter's health, Jan $3^{\text {rd }} 2002$.

[12] Krebs - Smith SM et al, (1997), "Characterizing food intake partners of American adults". Am. J. Clin. Nutrition 65 (Suppl), 1264s -1268 s.

[13] Palmer J, Leontos C. (1995) "Nutrition training for chefs: Taste as an essential determinant of choice”. J.Am Diet Assoc. 95: 1418 1421.

[14] Condrasky M, Ledikwe J.H. Flood JE, Rolls B.J (2007), “Chefs opinions of Restaurants portion sizes”. Obesity (Silver spring) Aug; 15 (18) 2086-94. 